\title{
Fundamentos filosóficos e antropológicos da Teoria do Se-movimentar e a formação de sujeitos emancipados, autônomos e críticos: o exemplo do currículo de Educação Física do Estado de São Paulo
}

\author{
Mauro Betti* \\ Jorge Knijnik ${ }^{* *}$ \\ Luciana Venâncio*** \\ Luiz Sanches Neto ${ }^{* * * *}$ \\ Jocimar Daolio ${ }^{* * * * *}$
}

\begin{abstract}
Resumo: Este artigo analisa os fundamentos filosóficos e antropológicos subjacentes à Teoria do Se-Movimentar com base na filosofia fenomenológica de Merleau-Ponty e na antropologia social de Mauss e Geertz. Considera também implicações para os currículos de Educação Física do ensino fundamental e médio que tenham por mote a formação de sujeitos emancipados, autônomos e críticos, tomando como exemplo o Currículo de Educação Física do Estado de São Paulo. Conclui que o currículo precisa imbricarse com a vida social dos alunos e levar em conta desafios e temas da sociedade contemporânea.

Palavras-chave: Movimento Humano. Fenomenologia. Antropologia Social. Currículo.
\end{abstract}

\section{INTRODUÇÃO}

Nas décadas de 1980 e 1990, a Educação Física (EF) brasileira viveu um momento de elaboração de propostas de renovação teórica e metodológica. Calcadas nas Ciências Humanas, e

\footnotetext{
*Departamento de Educação Física. Faculdade de Ciências de Bauru. Universidade Estadual Paulista (UNESP). Bauru, SP. Brasil. E-mail: maurobettiunesp@gmail.com

${ }^{* *}$ School of Education. University of Western Sydney. Penrith. New South Wales!' Sydney, Austrália. E-mail: J.Knijnik@uws.edu.au

${ }^{* * \star}$ Faculdade de Ciências e Tecnologia. Universidade Estadual Paulista. Presidente Prudente, SP, Brasil. E-mail: luciana_venancio@yahoo.com.br

****Instituto de Biociências. Universidade Estadual Paulista. Rio Claro, SP. Brasil. E-mail: luizitosanches@yahoo.com

*****Departamento de Educação Física e Humanidades. Faculdade de Educação Física. Universidade de Campinas. E-mail: jocimar.daolio@gmail.com
} 
valendo-se de diferentes bases teóricas, elas estabeleceram um contraponto pedagógico para as propostas tradicionais, fundadas em pressupostos biológicos e do treinamento esportivo, e influenciaram a elaboração de proposições didático-pedagógicas para a EF escolar.

Pedagogias críticas e emancipatórias começaram a exercer importante influência e a tensionar o campo. Tais abordagens propunham a "transformação social" como tema chave, sustentadas por aportes marxistas e neomarxistas, apropriados por meio de estudos da Pedagogia (LIBÂNEO, 1984; SAVIANI, 1985), tendo repercussões nas concepções pedagógicas de EF. Essa direção é bem evidente, por exemplo, em Soares (1992).

Outras fontes teóricas - como estudos etnográficos, sociologia sistêmica e fenomenologia - também foram consideradas para propor mudanças na EF. Os estudos etnográficos valorizaram a dinâmica da diversidade cultural das aulas de EF e as diferenças individuais, tendo como referência a noção de alteridade (DAOLIO, 1995). Já o interesse pela sociologia sistêmica contribuiu com um modelo didático-pedagógico que apontou a necessidade de compatibilizar finalidades e meios educacionais no currículo de EF (BETTI, 2009). A abordagem fenomenológica de Kunz (1991, 1994) apresentou tanto novas perspectivas para análise do "corpo em movimento" como encaminhamentos didáticos para os processos de ensino e aprendizagem em EF.

Portanto, podemos afirmar que o campo daEF no Brasil, naquelas décadas, foi influenciado por teorias críticas e emancipatórias com diferentes nuanças, embora a noção de "cultura", também com diferentes entendimentos, lhes seja comum (DAOLIO, 2004).

De fato, Pich (2005), ao investigar o conceito de "cultura corporal de movimento" na EF brasileira, constatou que o conceito de cultura guarda uma pluralidade de significados conforme a matriz epistemológica, e apontou para a necessidade de "esclarecer os pressupostos epistemológicos empregados para conceituar a cultura" (PICH, 2005, p. 110).

Movimento, Porto Alegre, v. 20, n. 4, p. 1631-1653, out./dez. de 2014. 
Este artigo propõe-se a, inicialmente, discutir os fundamentos filosóficos e antropológicos subjacentes à proposição "críticoemancipatória" apresentada por Kunz (1991, 1994), cujo fundamento assenta-se na "Teoria do Se-Movimentar" (TSM). Analisaremos os pressupostos filosóficos dos conceitos de corpo, movimento e cultura que sustentam a TSM, identificando suas bases na fenomenologia de Merleau-Ponty (1999, 2000, 2002); também buscaremos dialogar com a antropologia social de Mauss (2003) e Geertz (1989), já que a noção de "cultura" permeia a proposição crítico-emancipatória. Chegaremos então às noções de alteridade e intersubjetividade.

Um panorama das principais referências e conceitos fenomenológicos que aparecem nas publicações brasileiras que tratam da TSM já foi apresentado por Ghidetti, Almeida e Bracht (2013). Concluíram que se baseiam predominantemente no livro "Fenomenologia da Percepção" de Merleau-Ponty², e que os estudos relacionados à TSM precisam ser aprofundados em direção a textos posteriores daquele filósofo.

Também as relações entre Merleau-Ponty e a Antropologia Social já foram tratadas por Daolio, Rigoni e Roble (2012), os quais inicialmente apontaram que em "Signes" (1960), Merleau-Ponty reconheceu a importância da Antropologia para o esclarecimento do papel do observador em sua relação com o seu objeto pesquisado - na medida em que este último é também sujeito humano, não haveria mais que escolher entre o individual e o coletivo. Os autores identificaram aproximações e diálogos frutíferos entre a fenomenologia de Merleau-Ponty e a antropologia de Mauss, com relação aos temas do corpo, intersubjetividade, significação e cultura.

Atualmente há vários currículos regionais que incorporaram, em diferentes graus, os avanços teórico metodológicos da EF

'Utilizamos o termo "Se-Movimentar" conforme tradução da expressão original alemã "SichBewegen" proposta para a língua portuguesa por Kunz $(1991,1994)$.

${ }^{2} \mathrm{~A}$ publicação original é de 1945: MERLEAU-PONTY, Maurice. Phénoménologie de la perception. Paris: Editions Gallimard.

Movimento, Porto Alegre, v. 20, n. 4, p. 1631-1653, out./dez. de 2014. 
brasileira pautados nas Ciências Humanas. Com entendimentos diferenciados, a noção de cultura é comum à grande parte das propostas atuais do campo pedagógico-escolar da EF.

Consideramos que o desafio crucial para a EF é articular currículos na educação básica que sistematizem intencionalmente, em termos de conteúdos, estratégias e avaliação, a formação de sujeitos emancipados e autônomos, capazes de exercitar a crítica e a autocrítica ${ }^{3}$ no âmbito da cultura de movimento. $\mathrm{O}$ caso do Currículo de Educação Física do Estado de São Paulo ${ }^{4}$, que incorporou a TSM como referência principal, será apresentado na segunda parte de nossa análise como uma possibilidade curricular que aponta para essa direção.

Com base em Freire (1991, 2002) e Kunz (1991, 1994), entendemos que "emancipação" e "autonomia" estão enleados, constituem um único processo, sempre inacabado, de tomar consciência e pronunciar-se de forma singular, coletiva e crítica diante das objetivações e condicionamentos que as mídias, a indústria cultural e a ciência positiva impõem aos sujeitos. Buscar emancipação e autonomia na EF exige elevar a capacidade crítica dos sujeitos para tomarem decisões, fazerem escolhas, agirem e se pronunciarem no mundo.

\section{CoRpo, movimento e CULTURA nA TSM}

Nossa questão geral é: em que bases filosóficas e antropológicas ancoram-se as noções de corpo, movimento e cultura que transitam na TSM? Os critérios que perpassam nossa análise relacionam-se com a filosofia fenomenológica de Maurice Merleau-Ponty e com a antropologia social desenvolvida por Marcel Mauss e Clifford Geertz.

3Por "crítica" entendemos a capacidade de distinguir e valorar critérios de acordo com juízos de valor, e por "autocrítica" a capacidade de autoavaliar as relações travadas com as coisas e os outros humanos.

${ }^{4} \mathrm{O}$ referido currículo foi implementado em 2008 na rede pública estadual de São Paulo a partir do $6^{\circ}$ ano do ensino fundamental e ensino médio, e alcança cerca de 4.000 escolas.

Movimento, Porto Alegre, v. 20, n. 4, p. 1631-1653, out./dez. de 2014. 
A TSM iniciou-se com os holandeses Carl C. F. Gordijn ${ }^{5}$ - que fundamentou filosoficamente o ensino do movimento, elaborando uma concepção dialógica - e Jan W. Tamboer ${ }^{6}$, prosseguindo com o alemão Trebels (2006). O ponto inicial da TSM é a fenomenologia concebida por Maurice Merleau-Ponty, desdobrada da filosofia fenomenológica de Edmund G. A. Husserl (1859-1938). Tal teorização chegou ao Brasil por meio dos trabalhos de Kunz (1991, 1994, 2006), que enfatizam o movimento humano como expressão própria do sujeito, e não como uma parte predeterminada de modelos mecânicos, como fazem, por exemplo, as análises biomecânicas e comportamentalistas, que separam o movimento do sujeito-que-se-movimenta.

No campo da Antropologia Social, Mauss (2003)7 ampliou o conceito de cultura presente até então, ao considerar que as ações humanas são sempre manifestas em sua integridade, isto é, como "fatos sociais totais". Ou seja, as ações humanas constituem-se como fatos sociais e só podem ser compreendidas a partir das experiências individuais, considerando suas dimensões fisiológica, psicológica e social.

Geertz (1989) nos ajuda a compreender os pressupostos culturais da TSM, ao afirmar que a Antropologia deve deixar de ser uma ciência experimental em busca de leis, e almejar ser uma ciência interpretativa em busca do significado; e que a cultura é um processo contínuo e dinâmico de orientação e significação que os humanos empreendem o tempo todo de forma simbólica.

Correlativamente, esse processo de significação presente nas ações corporais é fundamental na obra de Merleau-Ponty,

${ }^{5}$ GORDIJN, Carl C. Friedrich. Inleiding tot het bewegingsonderwijs ["Introdução ao ensino do movimento"]. Baarn: [s.n.], 1968; GORDIJN, Carl C. Friedrich et al. Wat beweegt ons. ["O que nos move"] Baarn: [s.n.], 1975.

${ }^{6}$ TAMBOER, Jan W. Isaac. Sich-Bewegen - ein dialog zwischen mensch und welt ["Semovimentar: um diálogo entre o homem e o mundo"]. Sportpädagogik, [S.I.], n.3, v.2, p.60-65, 1979; TAMBOER, Jan W. Isaac. Mensbeelden aachter Bewegingsbeelden ["Concepções de homem e imagens de movimento"]. Haarlen: [s.n.], 1985.

${ }^{7}$ A publicação original é de 1925: MAUSS, Marcel. Essai sur le don: forme et raison de l'echange dans lês sociétés archaïques.

Movimento, Porto Alegre, v. 20, n. 4, p. 1631-1653, out./dez. de 2014. 
que elabora uma noção de corporeidade que considera o corpo como modo de apreensão sensível do significado, o qual não pode ser reduzido à ordem da natureza humana. Conforme entendem Daolio, Rigoni e Roble (2012, p.186) se, para Merleau-Ponty, “[...] as percepções e as apreensões do mundo estão fundamentadas num corpo biológico, concomitantemente elas são definidas pela sociedade e pela cultura específica de cada grupo".

Merleau-Ponty (1999, 2000, 2002) aborda o tema da percepção, do corpo, do movimento e da significação como um sistema de totalidade - uma Gestalt. Sua fenomenologia opõe-se a uma filosofia da consciência, e para ele o mundo não é "aquilo que eu penso, mas aquilo que eu vivo" (1999, p.14), e nossa imersão no mundo é fundamentalmente corporal. É no e com o corpo que me relaciono com o mundo e com outros humanos, que percebo e sou percebido, porque simultaneamente sou e tenho um corpo. Com isso, introduz-se a noção de ambiguidade entre corpo próprio e corpo objetivo.

O corpo objetivo é como um objeto qualquer do mundo, sobre o qual as ciências buscam analisar e explicar, e para as quais só existe conceitualmente. Já o corpo próprio é a função do corpo vivo, "a verdade do corpo tal como nós o vivemos" (1999, p. 578), é “um conjunto de significações vividas" (MERLEAU-PONTY,1999, p. 212). Assim, "a experiência do corpo próprio opõe-se ao movimento reflexivo [...] que nos dá apenas o pensamento do corpo ou o corpo em ideia, e não a experiência do corpo ou o corpo em realidade" (MERLEAU-PONTY 1999, p. 269). A experiência do mundo radica na experiência do próprio corpo, proporcionando um saber antepredicativo, que é anterior às nossas representações intelectuais sobre o mundo.

O tema da intencionalidade é caro à fenomenologia de Husserl, por isso sua "teoria da constituição", conforme Dartigues (1973), afirma que o sujeito se constitui pela reflexão sobre sua própria vida irrefletida, o que o levou a distinguir dois tipos de intencionalidade:

Movimento, Porto Alegre, v. 20, n. 4, p. 1631-1653, out./dez. de 2014. 
(i) temática: "aquela de nossos juízos e de nossas tomadas de posição voluntárias" (MERLEAU-PONTY, 1999, p.16), que é "saber do objeto e saber deste saber sobre o objeto" (DARTIGUES, 1973, p.54);

(ii) operante ou "em exercício": aquela "que forma a unidade natural e antepredicativa do mundo e de nossa vida", que aparece "em nossos desejos, nossas avaliações, nossa paisagem, mais claramente do que no conhecimento objetivo, e fornece o texto do qual nossos conhecimentos procuram ser a tradução em linguagem exata" (MERLEAU-PONTY, 1999, p.16).

Daí decorre a diferenciação entre significação existencial (que se refere aos vividos intuitivos, pré-reflexivos, nos quais o sentido equivale à existência) e significação conceitual (que agrega outros sentidos, à medida que é um saber intersubjetivo).

A reflexão - o saber consciente - "só se exerce sobre esse fundo de irreflexão, nessa dimensão da vida que já é sentido, porque visada de objeto, que já é uma perspectiva sobre o mundo, mas sentido ainda não formulado" (DARTIGUES, 1973, p.54). Para Merleau-Ponty (1999, p.16-18), é por conta da ampliação da noção de intencionalidade que a fenomenologia assume a gênese do sentido, pois "não há uma palavra, um gesto humano, mesmo distraídos ou habituais, que não tenham uma significação; não podemos fazer ou dizer nada que não adquira um nome na história".

Conforme Chaú (2000), Husserl explicitou que as significações, a princípio ideais e intemporais, são sedimentadas, mas também retomadas pela cultura, caminho continuado por Merleau-Ponty (1999, p.249), como se vê a seguir:

A nova intenção significativa só se conhece a si mesma recobrindo-se de significações já disponíveis, resultado de atos de expressão anteriores. As significações disponíveis entrelaçam-se repentinamente segundo uma lei desconhecida, e de uma vez por todas um novo ser cultural começou a existir.

Movimento, Porto Alegre, v. 20, n. 4, p. 1631-1653, out./dez. de 2014. 
Por outro lado, como essa análise fenomenológica situa a condição humana em algum lugar entre a natureza e a cultura, ela aponta a ambiguidade constitutiva do corpo próprio. Se o corpo não é um objeto, também "a consciência que tenho dele não é um pensamento" e, portanto, "sua unidade é sempre implícita e confusa"; está "enraizado na natureza no próprio momento em que se transforma pela cultura" (MERLEAU-PONTY, 1999, p.269). Tal entendimento reabre espaço para o estudo do corpo como organismo fisiológico, ao situá-lo simultaneamente na natureza e na cultura, sem incorrer no reducionismo tradicional das Ciências Biológicas.

Mas, para chegar a tal entendimento, conforme Chauí (2000), Husserl precisou demonstrar que a relação entre subjetividade solitária e mundo objetivo é a mesma para todos os sujeitos, afirmando que a subjetividade transcendental é intersubjetividade.

\section{Alteridade, intersubjetividade e TSM}

Tamboer (1979) retoma e aprofunda a "concepção dialógica de movimento" de Gordijn (1968), considerando que o movimento manifesta a correlação original ser humano-mundo, compreendendo o mundo pela ação. A partir dessa premissa ontológica, Gordijn conceitua o Se-Movimentar (SM) como um diálogo no qual ser humano e mundo participam na constituição do movimento; portanto, não podem ser isolados, pois cada um "significa" na relação com o outro.

O ser humano relaciona-se com algo exterior a ele próprio - outro humano ou coisas. Esse "Outro" é questionado pelo sujeito quanto ao seu significado - uma bola, por exemplo, pode ser questionada quanto à propriedade de rolar ou quicar. Posso falar sobre a bola ou olhá-la atentamente, mas só quando eu a faço quicar ou rolar é que questiono seu significado, e ela me "responde" algo, e as possíveis respostas só serão compreendidas se eu puder significá-las. O SM nasce então da totalidade (uma Gestalt) entre ser humano e mundo - a pessoa e a situação concreta

Movimento, Porto Alegre, v. 20, n. 4, p. 1631-1653, out./dez. de 2014. 
- que não pode ser conceituada como somatória de fatores isolados. Como acontecimento dialógico, trata-se de uma forma pessoalsituacional de significados. Para Kunz (1991, 1994, 2006), o SM é sempre dirigido a algo, mostra ou realiza algo, ou seja, é pleno de intencionalidade e significado.

Trebels (2006), por sua vez, chama a atenção para três aspectos importantes da concepção fenomenológica do movimento humano:

(a) preocupação com o sujeito do movimento;

(b) situar o ambiente do movimento (posição do ser diante da própria existência, do mundo);

(c) compreensão do significado do movimento.

Portanto, é na relação com as coisas do mundo e os outros que o ser humano expressa sua existência. $\mathrm{Na}$ EF isso precisa ser desvelado mediante as situações colocadas para os sujeitos nas aulas. Não basta analisar o deslocamento do corpo no espaço, é necessário compreender como o sujeito (autor) confronta o mundo e a própria existência no agir, expressando o significado do próprio movimento.

Contudo, Tamboer (1979) dirige duas observações críticas a Gordijn com as quais concordamos.

A primeira crítica refere-se à maior atenção que Gordijn dispensa ao SM em relação às "coisas" do mundo do que em relação às "pessoas", considerando duvidosa a sua tese de que, quer diga respeito a coisas ou pessoas, a estrutura da relação seja a mesma. Assim como Ghidetti, Almeida e Bracht (2013) consideramos a hipótese de que, para a concepção dialógica do movimento dar conta da relação com o Outro humano, seria necessário levar em conta textos póstumos de Merleau-Ponty (2000, 2002). Pois, se para Merleau-Ponty o Outro humano é também uma coisa entre as outras coisas do mundo, é, todavia, uma "coisa" especial, pois nunca se revela totalmente para mim, permanece sempre um resíduo de mistério, aspectos vinculados aos temas da alteridade

Movimento, Porto Alegre, v. 20, n. 4, p. 1631-1653, out./dez. de 2014. 
e intersubjetividade que o filósofo aprofundou posteriormente no livro "Fenomenologia da Percepção".

Para Daolio, Rigoni e Roble (2012, p. 186), se para Merleau-Ponty o corpo é pleno de subjetividade, ele reconhece a intersubjetividade "marcada numa condição 'corpórea' que se dá entre ações individuais e coletivas", aspecto que evidenciaria a influência da Antropologia Social na sua fenomenologia, "justamente por promover a dissolução de uma ideia de sentido que é apenas interna".

Em perspectiva similar avançaram outros autores (BETTI et al., 2007; KNIJNIK, 2009; ZIMMERMMAN; MORGAN, 2011), ao apontarem a intersubjetividade como dimensão fundamental nos jogos e esportes coletivos. É na relação com o outro que me abro para o mundo, percebo a presença desse outro em mim e, ao mesmo tempo, vejo-me limitado por ele, abrindo assim a possibilidade de tornar-me singular (MERLEAU-PONTY, 2000).

Por exemplo, para Betti et al. (2007), quando se trata de um jogo/esporte coletivo com bola, a relação do jogador com a bola não é uma conexão "direta" e "pura", mas se dá por meio dos movimentos que rearranjam constantemente as relações entre os jogadores e a bola. Pois a bola, que é percebida por mim, como jogador, também o é pelos outros jogadores - na linguagem fenomenológica, ela é universal. Então, "ensaiamos" a jogada do outro, experimentamo-nos no corpo do outro. Mas se o outro jogador realiza um gesto inesperado para mim (por exemplo, uma nova forma de driblar), logo percebo que não posso controlá-lo ou antecipar uma resposta. Assim, a posteriori, crio um signo para preencher a lacuna que se formou entre nós (por exemplo, um modo de evitar o drible). Nessa perspectiva, há uma significação que vai sendo refeita, conforme as situações de jogo vão se apresentando de modos diferentes.

Podemos dizer que, na transcendência, nossas intuições são confirmadas; portanto não existe a coisa "em si", mas relações que possibilitam novas significações sobre algo no mundo. Então, se

Movimento, Porto Alegre, v. 20, n. 4, p. 1631-1653, out./dez. de 2014. 
posso me transcender em direção ao mundo e ao outro, eu tenho possibilidades e as possibilidades do mundo são também minhas, pois somos feitos da mesma carne e por isso o mundo inteiro se fala em mim (MERLEAU-PONTY, 2000).

A segunda crítica de Tamboer a Gordijn diz respeito à concepção do SM como um diálogo do sujeito diretamente com o mundo dos significados motores. Embora admita que esse diálogo é codeterminado por uma realidade histórica, social e econômica, Gordijn não se dispôs a analisar esse aspecto. O conceito de Cultura de Movimento (CM) vem em resposta a essa limitação.

No entendimento de Kunz (1991, 1994), a CM constitui-se na dialética entre o mundo fenomenológico dos movimentos conceito derivado da noção de "mundo vivido" (Lebenswelt) ${ }^{8}-$ e as objetivações ou condicionamentos culturais do movimento que provêm da ciência positiva, da tecnologia, das mídias e do treinamento esportivo. Essas agências, a partir de seus próprios interesses e ideologias, tornam hegemônicos significados que condicionam e restringem o SM, dificultando o processo de emancipação e autonomia dos sujeitos.

Assim, com base nas concepções de SM e CM, Kunz elaborou sua proposição "crítico-emancipatória" para a EF. Esta considera o contexto sociocultural e a necessidade de emancipar os sujeitos por meio do questionamento crítico dos significados dos movimentos (nos esportes, lutas, danças etc.) e construção de significados pessoais-situacionais na experiência do movimento, para que possam fazer frente aos interesses e significados hegemônicos.

Já na perspectiva da Antropologia Social, Geertz (1989) aprofunda a questão da intersubjetividade a partir da relação pesquisador-pesquisado, porque é no ato da interpretação proposto pela pesquisa antropológica que o pesquisador assume sua subjetividade, procurando considerar também a do pesquisado.

\footnotetext{
${ }^{8}$ Segundo Thiele (apud KUNZ, 1991), Husserl caracteriza o Lebenswelt como um "estilo global" que diferencia as pessoas no mundo cotidiano; representa, assim, a "redução" fenomenológica deste mundo e é, ao mesmo tempo, um horizonte não tematizado de todo indivíduo.
}

Movimento, Porto Alegre, v. 20, n. 4, p. 1631-1653, out./dez. de 2014. 
Embora o autor tenha se referido à relação pesquisador-pesquisado, a questão da intersubjetividade pode ser expandida também para a relação pedagógica professor-aluno.

Como bem salienta Oliveira (1988) - um dos principais comentadores da obra de Geertz no Brasil - é no ato da interpretação (podemos também dizer, da aula) que o pesquisador (também o professor e o aluno), exercita sua intersubjetividade, a partir da interiorização do tempo, não de um tempo estático já passado nem de um tempo objetivo dividido em etapas evolutivas, mas um tempo no qual o pesquisador se insere, assumindo sua condição e seu momento histórico no ato da interpretação. Segundo o autor, se os paradigmas da ordem na Antropologia domesticaram a subjetividade (pela busca incessante da objetividade), o indivíduo (a partir de explicações psicológicas que desconsideravam sua vinculação social) e a história (a partir da consideração de um tempo estático que previa e controlava comportamentos humanos), com a antropologia interpretativa de Geertz esses elementos são transformados, respectivamente, em intersubjetividade (subjetividade socializada), individualidade (indivíduo socializado) e historicidade (história interiorizada).

Com essas considerações, não estamos afirmando conclusivamente que o conceito de CM de Kunz é o mesmo presente na Antropologia de Geertz, mas que esta ajuda a compreender os pressupostos culturais da TSM.

A seguir, tomaremos o Currículo de Educação Física do Estado de São Paulo (CEF-SP) como exemplo. Serão consideradas algumas implicações dos fundamentos antropológicos e fenomenológicos ora apresentados e debatidos para a construção de um currículo de EF para o ensino fundamental (a partir do $6^{\circ}$ ano) e médio que tenha por mote a formação de sujeitos emancipados, autônomos, e (auto)críticos.

Estamos cientes que a direção teórico-metodológica proposta pelo CEF-SP tem sido objeto de estudos críticos, os quais chegaram a conclusões diferentes. Por exemplo, Lippi (2009) situa o CEF-SP

Movimento, Porto Alegre, v. 20, n. 4, p. 1631-1653, out./dez. de 2014. 
no contexto do capitalismo neoliberal, no qual a função da educação escolar é preparar os trabalhadores para o mercado globalizado, por meio de uma "pedagogia das competências.” Já Liba (2012), conclui que o CEF-SP possibilita a aquisição do "conhecimento poderoso" capaz de levar o aluno a fazer generalizações e ampliar seus horizontes no âmbito da cultura corporal de movimento, em especial porque propõe o estreitamento das relações entre o "saber fazer" (prática) e o "saber sobre o fazer" (teoria) ${ }^{9}$.

\section{EM BUSCA DO SUJEITO EMANCIPADO, AUTÔNOMO E CRÍTICO: O CASO DO CEF-SP}

CM e SM são os dois conceitos que subsidiam o CEF-SP. Por CM, o CEF-SP entende "o conjunto de significados/sentidos, símbolos e códigos que se produzem e reproduzem dinamicamente nos jogos, esportes, danças e atividades rítmicas, lutas, ginásticas etc., os quais influenciam, delimitam, dinamizam e/ou constrangem o SM dos sujeitos, base de nosso diálogo expressivo com o mundo e com os outros" (SÃO PAULO, 2008, p.43). O SM é entendido como "a expressão individual e/ou grupal no âmbito de uma cultura de movimento; é a relação que o sujeito estabelece com essa cultura a partir de seu repertório (informações/conhecimentos, movimentos, condutas etc.), de sua história de vida, de suas vinculações socioculturais e de seus desejos" (SÃO PAULO, 2008, p.43).

Não é novidade afirmar que um currículo escolar - seja de $\mathrm{EF}$ ou de qualquer outro componente - possui um pressuposto cultural. O próprio papel da instituição escolar impõe para seus componentes curriculares uma abordagem cultural, dessa forma preservando as tradições culturais, transformadas em conteúdos escolares, para que os alunos sejam inseridos no universo da

\footnotetext{
${ }^{9}$ Foge ao escopo deste estudo uma análise extensiva e aprofundada desses e outros estudos sobre a CEF-SP. Nosso foco é, repetimos, apresentar o currículo paulista como uma direção teórico-metodológica que, com os fundamentos antropológicos e fenomenológicos já explicitados, aponta para a possibilidade de formação de sujeitos emancipados, autônomos, e (auto)críticos.
}

Movimento, Porto Alegre, v. 20, n. 4, p. 1631-1653, out./dez. de 2014. 
vida humana, possam desenvolver toda sua potencialidade e tenham melhores condições de acesso à condição de cidadãos (GONZÁLEZ; FENSTERSEIFER, 2009).

No CEF-SP a noção de cultura é ancorada na Antropologia Social de Mauss e Geertz. Mauss (2003), para quem as ações humanas são "fatos sociais totais", chegou à noção de técnicas corporais como construções humanas tradicionais que não se explicam somente pelas ciências naturais. Os seres humanos constroem suas técnicas corporais de forma contextual considerando os usos específicos do corpo, seus significados e valores. Ou seja, os gestos humanos, mais que conexões musculares ou nervosas, são expressões que fazem sentido nos diversos contextos humanos.

Isso está expresso no CEF-SP quando afirma que “[...] há que se considerar os processos de significação, ou seja, aquilo que dá sentido a determinadas ações corporais. Em outros termos, o que dá sentido ao movimentar-se humano é o contexto em que ele ocorre [...].", e a partir desse pressuposto o CEF-SP entende que a “[...] Educação Física deva tratar pedagogicamente de conteúdos culturais relacionados ao movimentar-se humano, porque $o$ ser humano, ao longo de sua evolução de milhões de anos, foi construindo certos conhecimentos ligados ao uso do corpo e ao seu movimentar-se" (SÃO PAULO, 2008, p.42).

Em consonância com a noção de cultura de Geertz, o CEF-SP propõe como objetivo para o ciclo II do Ensino Fundamental $\left(6^{\circ}\right.$ ao $9^{\circ}$ anos ) "[...] evidenciar os significados/sentidos e intencionalidades" já presentes nas experiências e na cultura de movimento dos alunos "cotejando-os com os significados/sentidos e intencionalidades presentes nas codificações das culturas esportiva, lúdica, gímnica, das lutas e rítmica", bem como "[...] diversificar, sistematizar e aprofundar as experiências do Se-Movimentar", proporcionando aos alunos novas experiências de movimento, de modo a possibilitar "novas significações" e "re-significar experiências já vivenciadas" (SÃO PAULO, 2008, p. 44-45). E para o ensino médio propõe:

Movimento, Porto Alegre, v. 20, n. 4, p. 1631-1653, out./dez. de 2014. 
possibilitar aos alunos o "alargamento das possibilidades do Se-Movimentar e dos significados/sentidos das experiências de movimento no jogo, esporte, ginástica, luta e atividade rítmica, rumo à construção de uma autonomia crítica e autocrítica" (SÃO PAULO, 2008, p.46).

O cotejamento proposto entre os significados/sentidos e intencionalidades dos sujeitos em relação às suas experiências do SM e os significados/sentidos e intencionalidades presentes nas culturas esportiva, lúdica etc. considera, inicialmente, a aula como espaço e tempo vivo de mediação no plano simbólico da cultura humana; em segundo lugar, o aluno como sujeito dinâmico e dotado de significações a respeito de seu SM no mundo; em terceiro lugar, a relação professor-aluno e aluno-aluno como essencialmente intersubjetiva, relação esta capaz de criar e recriar novos significados culturais. Dessa forma, pretende-se que a EF escolar seja aproximada da vida dos alunos, gerando possibilidades de novos diálogos e novos sentidos ao seu SM. Por isso, o CEF-SP também ressalta "[...] a possibilidade do Se-Movimentar no âmbito da cultura de movimento juvenil ser cotejada com outras dimensões do mundo contemporâneo" (SÃO PAULO, 2008, p.46).

Para viabilizar tais objetivos e princípios, o CEF-SP propõe uma estrutura que inter-relaciona um eixo de conteúdos (Jogo; Esporte; Ginástica; Luta; Atividade Rítmica) definidos a partir da tradição da EF, e um eixo de temas delimitados pela sua atualidade e relevância na sociedade (Organismo Humano, Movimento e Saúde; Corpo, Saúde e Beleza; Contemporaneidade; Mídias; Lazer e Trabalho).

A Figura 1 apresenta as inter-relações dinâmicas entre os conteúdos e os temas. Por exemplo, das relações entre o conteúdo "Esporte" e o tema "Mídia" pode emergir o subtema ou subconteúdo "espetacularização do esporte"; entre "Dança" e "Contemporaneidade", o subtema "gênero"; entre "Ginástica" e "Corpo, Saúde e Beleza", os "modelos e padrões de beleza"; entre "Jogo" e "Lazer e Trabalho", a "presença do jogo/lúdico no tempo livre", e assim por diante.

Movimento, Porto Alegre, v. 20, n. 4, p. 1631-1653, out./dez. de 2014. 
Figura 1. Inter-relações de temas e conteúdos no CEF-SP

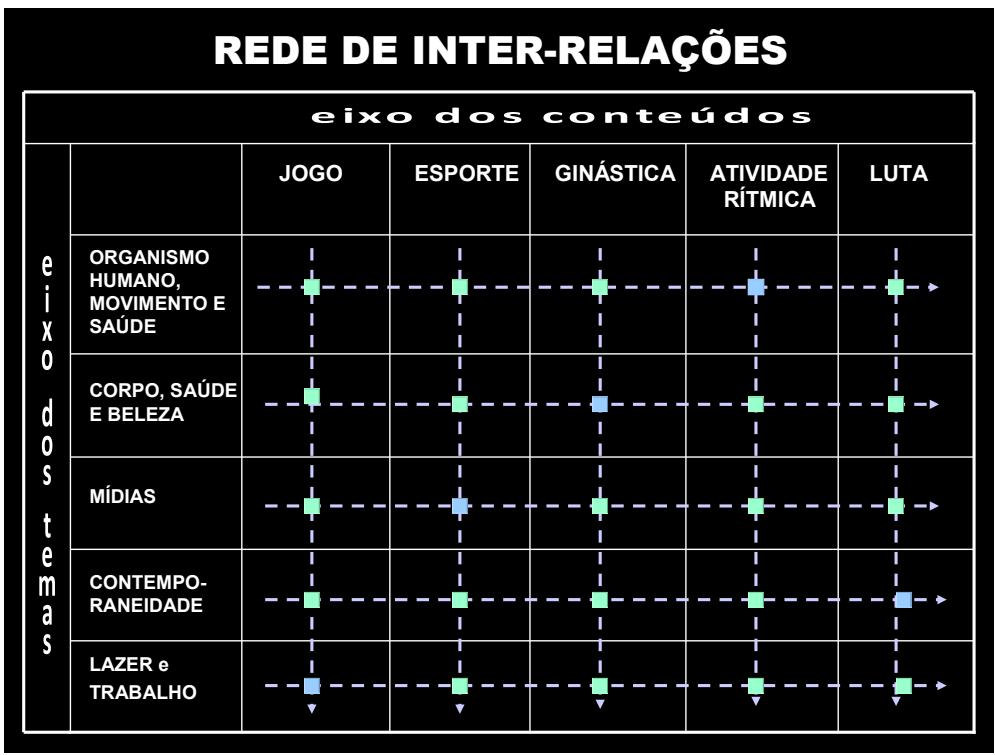

Fonte: Adaptado de Betti et al. (2010, p. 113).

A tradição da EF está ancorada nas concepções do corpo como máquina e no movimento como fenômeno meramente físico, desconsiderando as influências do ambiente cultural, fragmentando o do ser humano e distanciando-o da compreensão da própria existência. O CEF-SP situa-se como exemplo de proposição teóricometodológica que contribui para romper asserções dicotômicas no trato da EF, ao tratar concomitantemente "corpo", "movimento", "cultura", "sujeito" e "mundo".

Os pressupostos filosóficos e antropológicos do CEF-SP acenam para a valorização do sujeito, para as condições existenciais dos alunos, para que se tornem (auto)críticos nos processos decisórios. É ressaltado que não basta ao aluno "saber sobre". Por exemplo, não é suficiente saber sobre o esporte, a luta, a dança ou a ginástica, ou saber sobre o corpo, porque isso caracterizaria, na linguagem merleau-pontyana, apenas as significações conceituais. Deseja-se, no sentido mais crítico, elaborar conhecimentos com

Movimento, Porto Alegre, v. 20, n. 4, p. 1631-1653, out./dez. de 2014. 
as experiências (de movimento) vividas nas aulas de EF, ou seja, quem sabe sobre não sabe de, não vivenciou, não travou relação na experiência de e com o mundo, não constituiu significações existenciais, sem as quais as significações conceituais constituem mero intelectualismo.

Nessa direção, a proposição crítico-emancipatória de Kunz (1994, 2006), fundamentada nos conceitos de SM e CM, aponta princípios didáticos na EF que apoiam a busca da formação voltada à emancipação, à autonomia e à criticidade:

- identificar o significado central dos movimentos, evidenciando sua intencionalidade original; por exemplo, a intenção do salto em distância é saltar o mais longe possível, e não saltar mais que outra pessoa, como na competição esportiva;

- descobrir formas alternativas de realizar movimentos com sucesso;

- compartilhar coletivamente as descobertas e significados, por meio da linguagem verbal e/ou da linguagem do movimento;

- questionar o significado cultural dos movimentos.

A contribuição para a emancipação, autonomia e criticidade dar-se-ia a partir da compreensão das intencionalidades (temática e/ou operante, na linguagem merleau-pontyana) no âmbito do processo de significação do movimento pelo sujeito.

É preciso também estar atento para o fato de que perseguir a "tradução" de tudo que é vivido em palavras pode gerar obstáculos para o entendimento e valoração das experiências vividas na EF, as quais não são facilmente comunicáveis pela linguagem escrita e falada. Nesse caso, desconsideram-se as autorias dos sujeitos, que criam outras formas expressivas. É preciso torná-las cognoscíveis aos alunos perante as finalidades educativas da escola, o que também pode ser alcançado pelas palavras, mas não só.

Como é próprio do gesto humano "significar para além de sua simples existência de fato, inaugurar um sentido" (MERLEAUPONTY, 2002, p. 106), resulta que todos os gestos são comparáveis, que todo gesto é, de antemão, "aliado ou cúmplice de todas as outras

Movimento, Porto Alegre, v. 20, n. 4, p. 1631-1653, out./dez. de 2014. 
tentativas de expressão". Portanto, confrontar vivências e formas do SM, consigo mesmo e com outrem, por meio da fala ou outras linguagens, são todos modos de expressão da existência (BETTI et al., 2007).

Por isso, as situações de ensino e aprendizagem propostas nas aulas de EF não devem opor o "cognitivo" ao "motor", a linguagem verbal/escrita à linguagem do movimento. Tampouco devem dissociar intencionalidades operantes e intencionalidades temáticas, ou significações existenciais e significações conceituais.

São essas, pois, em nosso entendimento, as condições que devem permear os currículos de EF na educação básica - aqui exemplificados com o caso do CEF-SP - quando se pretende que os alunos construam, na vida social, o processo de emancipaçãoautonomia caracterizado pela crítica (capacidade de distinguir e valorar critérios) e autocrítica (capacidade autoavaliar as relações travadas com as coisas e os outros humanos).

\section{Conclusões}

Consideramos que a compreensão das bases filosóficas e antropológicas da TSM nos possibilita ir além dos dualismos que muitas vezes caracterizam as práticas escolares e suas representações, e que findam por bloquear avanços teórico-metodológicos. Neste estudo, a qualificação da EF como área de saber no currículo escolar buscou evitar dicotomias, e abarcar a totalidade das relações dos alunos consigo mesmos, com os outros no mundo, por meio do movimento concebido como fenômeno cultural. O que não se pode negar, contudo, é que essas relações, por serem humanas, possuem todas as ambiguidades inerentes à nossa existência.

Por sua vez, emancipação e autonomia não são processos individuais, pois pressupõem a presença do outro - o outro coletivo - em busca de compartilhamentos. Trata-se da relação entre sujeitos que se reconhecem um no outro e entre si, e que, com suas capacidades de reflexão e ação conseguem discernir criticamente

Movimento, Porto Alegre, v. 20, n. 4, p. 1631-1653, out./dez. de 2014. 
em prol de um ideal coletivo. Para nós, emancipação e autonomia vão ao encontro da capacidade de agir por si com os outros, de poder fazer escolhas, pronunciar-se, de saber-se no e com o mundo de maneira sensível, crítica e ética.

Ser emancipado e autônomo na EF é viver e compartilhar experiências culturais de movimento que remetam ao corpopróprio do sujeito, que expressem sua existência na relação consigo mesmo e com o outro. Em um país como o Brasil, marcado por processos históricos de desigualdades, as contribuições de uma EF emancipatória e libertadora só poderão concretizar-se se houver condições para que os sujeitos se pronunciem no mundo. Esse pronunciamento poderá ser feito se o currículo propiciar intencionalmente aos alunos experiências do SM - no jogo, no esporte, na ginástica, na luta e na dança - que lhes possibilitem tecer os elos de significação da rede de inter-relações entre conteúdos e temas, tal como proposto pelo CEF-SP, os quais remetem à mídia, ao lazer e trabalho, à saúde e beleza, às questões da contemporaneidade (gênero, violência, virtualização do corpo etc.) e ao funcionamento do organismo humano.

A EF precisa estar imbricada na vida social dos sujeitos, levando em conta alguns desafios que a sociedade contemporânea nos apresenta, quanto à ética, diversidade e formas de comunicação: $1^{\mathrm{o}}$ - Educar os alunos para as dimensões éticas e políticas: a inter-relação entre o eixo dos conteúdos da EF e o eixo temático (Organismo Humano, Movimento e Saúde; Corpo, Saúde e Beleza; Contemporaneidade; Mídias; Lazer e Trabalho) pode fomentar esse processo de modo diversificado e atualizado.

$2^{\circ}$ - Ensinar considerando as idiossincrasias dos alunos, caracterizadas pela diversidade cultural: a diversidade de experiências e significações vividas pelos sujeitos deve ser promovida, no sentido de fomentar a criticidade em face dos padrões culturais homogeneizadores que limitam o SM.

$3^{\circ}$ - Fomentar possibilidades de comunicação e autoconhecimento por diversas formas de linguagens: as experiências corporais não se

Mbvimento, Porto Alegre, v. 20, n. 4, p. 1631-1653, out./dez. de 2014. 
comunicam facilmente pelo discurso escrito ou falado, e implicam dimensões subjetivas do humano.

Por fim, apontamos para a formação de um sujeito pleno de experiências vividas e comunicadas na relação com o outro. Se o princípio da alteridade nos ensina que o outro sou eu mesmo, por outro lado nem eu mesmo me conheço totalmente. Por isso, as situações de estresse, de esforço por aprender, comum nas situações de jogo, esporte, ginástica, dança e luta, podem revelar possibilidades, em mim mesmo e no outro, que eu desconhecia. Cabe à EF torná-las cognoscíveis por meio da reflexão alimentada por diversas linguagens, em direção à formação do sujeito emancipado, autônomo, crítico e autocrítico.

Contudo, não ousamos afirmar que o CEF-SP ou qualquer outro que aponte para a emancipação, autonomia e criticidade dos sujeitos consigam concretizar, de fato, o que aqui foi apontado como uma possibilidade teórica e uma intencionalidade políticopedagógica. Tal concretização exigiria outras ações no campo das políticas educacionais, e, do ponto de vista da investigação científica, estudos empíricos específicos.

Philosophical and anthropological foundations of Sich-
bewegen Theory and the formation of emancipated,
autonomous and critical subjects: the example of Physical
Education curriculum in the State of São Paulo
Abstract: This article examines philosophical and anthropological
underpinnings of the Sich-Bewegen Theory, based on the
phenomenological philosophy by Merleau-Ponty and social
anthropology by Mauss and Geertz. It also considers implications
for Physical Education Elementary and High School curricula aimed
at forming emancipated, autonomous and critical individuals, taking
the Physical Education Curriculum of the State of São Paulo as
example. It concludes that the curriculum needs to imbricate into
students' social life and take into account the challenges and issues
from contemporary society.
Keywords: Human Movement. Phenomenology. Social
Anthropology. Curriculum.

Movimento, Porto Alegre, v. 20, n. 4, p. 1631-1653, out./dez. de 2014. 


\begin{tabular}{|c|}
\hline $\begin{array}{l}\text { Fundamentos filosóficos y antropológicos de la Teoría } \\
\text { del Sich-bewegen y la formación de sujetos emancipados, } \\
\text { autónomos y críticos: el ejemplo del currículo de Educación } \\
\text { Física en el Estado de São Paulo } \\
\text { Resumen: Este artículo examina los fundamentos filosóficos y } \\
\text { antropológicos subyacentes a la Teoría del Sich-Bewegen, basado } \\
\text { en la filosofía fenomenológica de Merleau-Ponty y la antropología } \\
\text { social de Mauss y Geertz. También considera las implicaciones } \\
\text { para los programas de Educación Física en la escuela primaria y } \\
\text { secundaria, cuyo lema sea la formación de sujetos emancipados, } \\
\text { autónomosy críticos, tomando el ejemplo del Currículo de Educación } \\
\text { Física del Estado de São Paulo. Concluye que el currículo debe } \\
\text { imbricarse con la vida social de los estudiantes y tener en cuenta } \\
\text { los desafíos y problemas de la sociedad contemporánea. } \\
\text { Palabras clave: Movimiento Humano. Fenomenología. }\end{array}$ \\
\hline
\end{tabular}

\section{REFERÊNCIAS}

BETTI, Mauro. Educação física e sociedade. 2. ed. São Paulo: Hucitec, 2009.

BETTI, Mauro et al. Por uma didática da possibilidade: implicações da fenomenologia de Merleau-Ponty para a educação física. Revista Brasileira de Ciências do Esporte, Porto Alegre, v.28, n.2, p.39-53. jan. 2007. Disponível em: <http://rbceonline.org.br/revista/index.php/RBCE/article/view/54/62. Acesso em: 10 fev.2014.

BETTI, Mauro et al. A proposta curricular de educação física do estado de São Paulo: fundamentos e desafios. In: CARREIRA FILHO, Daniel; CORREIA, Walter Roberto. Educação física escolar: docência e cotidiano. (Org.). Curitiba: CRV, 2010. p. 109-128.

CHAUÍ, Marilena de Souza. Vida e obra. In: LOPARIC, Zeljko; LOPARIC, Andréa M. A. de Campos (Org.). Edmund Husserl. São Paulo: Nova Cultural, 2000. p. 5-15. (Os Pensadores).

SOARES, Carmem Lucia et al. Metodologia do ensino de educação física. São Paulo: Cortez, 1992.

DAOLIO, Jocimar. Da cultura do corpo. Campinas: Papirus, 1995.

DAOLIO, Jocimar. Educação física e o conceito de cultura. Campinas: Autores Associados, 2004.

DAOLIO, Jocimar; RIGONI, Ana C. Carolina; ROBLE, Odilon José. Corporeidade: o legado de Marcel Mauss e Maurice Merleau-Ponty. Pro-Posições, Campinas, v.

Movimento, Porto Alegre, v. 20, n. 4, p. 1631-1653, out./dez. de 2014. 
23, n. 3, p. 179-193, set./dez. 2012. Disponível em: < http://www.scielo.br/pdf/pp/ v23n3/11.pdf >. Acesso em: 20 nov.2013.

DARTIGUES, André. O que é fenomenologia? 2. ed. Rio de Janeiro: Eldorado Tijuca, 1973.

FREIRE, Paulo. Pedagogia do oprimido. 19. ed. São Paulo: Paz e Terra, 1991.

FREIRE, Paulo. Pedagogia da autonomia: saberes necessários à pratica educativa. 22. ed. São Paulo: Paz e Terra, 2002.

GEERTZ, Clifford. A interpretação das culturas, Rio de Janeiro : Guanabara Koogan, 1989.

GHIDETTI, Felipe Ferreira; ALMEIDA, Felipe Quintão de; BRACHT,Valter. A presença da fenomenologia na/da teoria do se-movimentar humano (TSMH) brasileira. Pensar a Prática, Goiânia, v. 16, n. 3, p. 886-902, jul./set. 2013. Disponível em: <http://www.revistas.ufg.br/index.php/fef/article/view/19554/15257>. Acesso em: 14 out.2013.

GONZÁLEZ, Fernando; FENSTERSEIFER, Paulo Evaldo. Entre o "não mais" e o "ainda não": pensando saídas do não -lugar da EF escolar. Cadernos de Formação RBCE, Campinas, v.1, n.1, p.9-24, set. 2009. Disponível em: <http:// www.rbceonline.org.br/revista/index.php/cadernos/article/view/978/561>. Acesso em 16 jan. 2014.

GORDIJN, Carl C. Friedrich. Inleiding tot het bewegingsonderwijs. Baarn: [s.n.], 1968.

KNIJNIK, Jorge. Handebol. São Paulo: Odysseus, 2009.

KUNZ, Elenor. Educação física: ensino \& mudança. ljuí: Unijuí, 1991.

KUNZ, Elenor. Transformação didático-pedagógica do esporte. Ijuí: Unijuí, 1994.

KUNZ, Elenor. Pedagogia do esporte, do movimento humano ou da educação física? In: KUNZ, Elenor; TREBELS, Andreas. H. (Org.). Educação física críticoemancipatória. ljuí: Unijuí, 2006. p.11-22.

LIBA, Flávia R. Torezin. A relação entre o "saber fazer" e o "saber sobre o fazer" no discurso pedagógico oficial da Educação Física escolar. Tese (Doutorado em Educação) - Pontifícia Universidade Católica de São Paulo, São Paulo, 2012.

LIBÂNEO, José Carlos. Democratização da escola pública: a pedagogia crítica dos conteúdos. 12. ed. São Paulo: Loyola, 1984.

LIPPI, Bruno G. Formação contínua de professores de educação física no Estado de São Paulo: quais as políticas em jogo? Dissertação (Mestrado em Educação) - Faculdade de Educação, Universidade de São Paulo, São Paulo, 2009. 
Fundamentos filosóficos e antropológicos da...

MAUSS, Marcel. Ensaio sobre a dádiva: forma e fazão da troca nas sociedades arcaicas. In: p. $183-294$. . Sociologia e antropologia. São Paulo: Cosac Naify, 2003.

MERLEAU-PONTY, Maurice. Fenomenologia da percepção. 2. ed. São Paulo: Martins Fontes, 1999.

MERLEAU-PONTY, Maurice. O visível e invisível. São Paulo: Perspectiva, 2000.

MERLEAU-PONTY, Maurice. O homem e a comunicação: a prosa do mundo. São Paulo: Cosac e Naify, 2002.

PICH, Santiago. Cultura corporal de movimento. In: GONZÁLEZ, Fernando; FENSTERSEIFER, Paulo Evaldo. (Org.). Dicionário crítico de educação física. Ijuí: Ed. Unijuí, 2005. p. 108-111.

SÃO PAULO (Estado), Secretaria da Educação. Proposta curricular do Estado de São Paulo: educação física - ensino fundamental ciclo Il e ensino médio. São Paulo: Secretaria de Estado da Educação, 2008. Disponível em: <http://www. educacao.sp.gov.br/portal/projetos/curriculo-do-estado-de-sao-paulo>. Acesso em: 28 mar. 2013.

SAVIANI, Dermeval. Escola e democracia. São Paulo: Cortez, 1985.

TAMBOER, Jan W. Isaac. Sich-Bewegen - ein dialog zwischen mensch und welt. Sportpädagogik, Hamburg, n.3, v.2, p.60-65, 1979.

TREBELS, Andreas H. A concepção dialógica do movimento humano: uma teoria do "se-movimentar". In: KUNZ, E.; TREBELS, A. H. (Orgs.). Educação física crítico-emancipatória. ljuí: Unijui, 2006. p.23-48.

ZIMMERMMAN, Ana Cristina; MORGAN, John. The possibilities and consequences of understanding play as dialogue. Sport, Ethics and Philosophy, London, v. 5, n. 1, p. 46-62, 2011. Disponível em: <http://www.nottingham.ac.uk/education/ documents/research/unesco/playasdialogue.pdf>. Acesso em: 2 set.2013.

Endereço para correspondência:

Av. Eng. Luiz E. C. Coube, 14-01-Vargem Limpa

17033-360 Bauru-SP

Recebido em: 30.04.2014

Aprovado em: 18.08.2014

Movimento, Porto Alegre, v. 20, n. 4, p. 1631-1653, out./dez. de 2014. 